\title{
Atrial Septum Hematoma \\ - Another Way to Die in Acute Aortic Dissection -
}

Juan Carlos Gómez-Polo, MD; Isidre Vilacosta, MD, PhD; Estela Aguilar-Navarro, MD;

Carlos Ferrera, MD, PhD; Sandra Rosillo, MD; Guillermo García-Diego, MD;

Carmen Olmos, MD, PhD; Pedro Martínez-Losas, MD; David Vivas, MD, PhD;

Francisco J. Noriega-Sanz, MD, PhD; Ana Viana-Tejedor, MD, PhD; Luis Ortega, MD, PhD
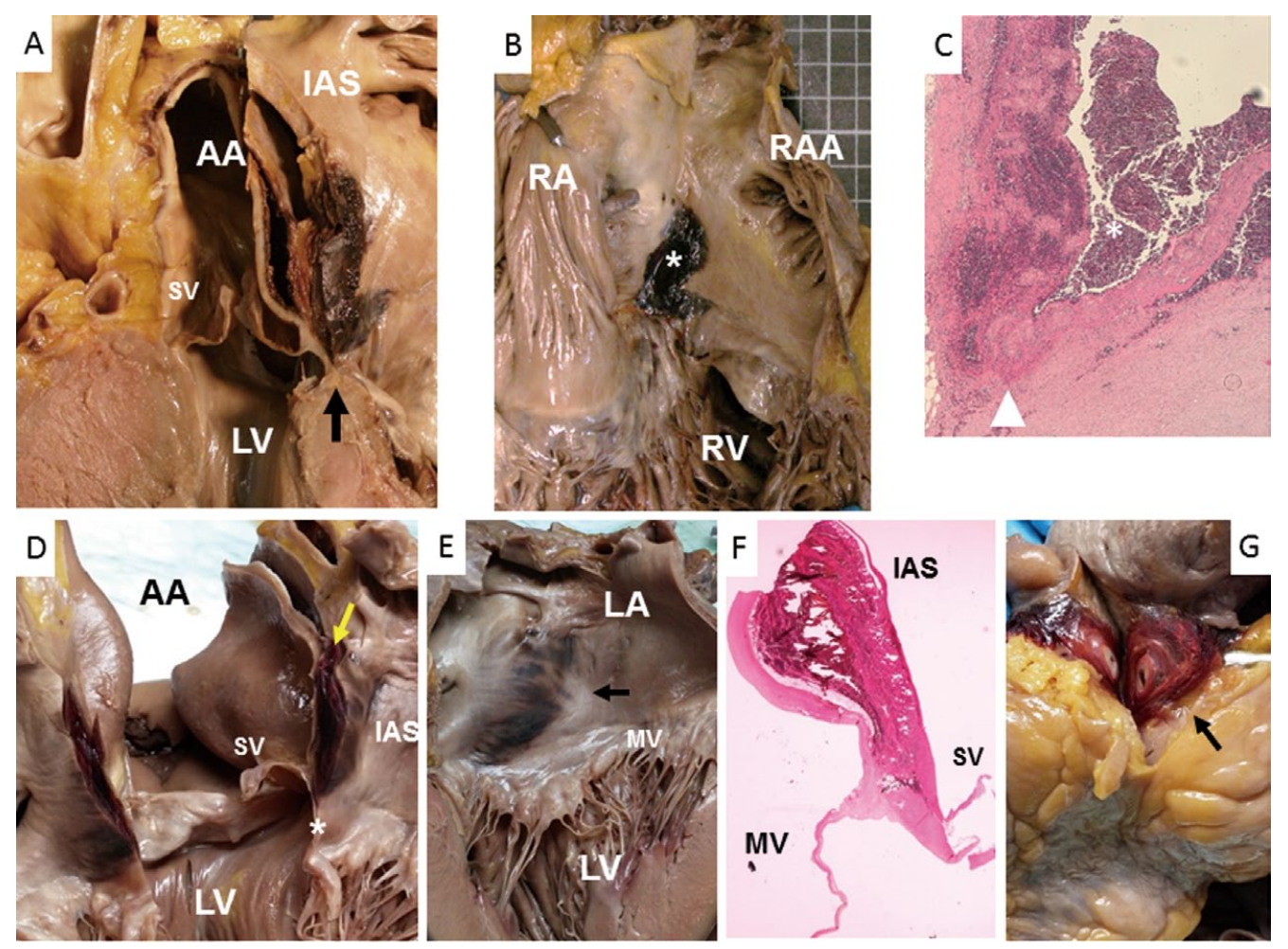

Figure. (A-C) Patient 1 and (D-G) patient 2. (A) Patient 1: dissecting hematoma spreading to the aortoatrial space and reaching the area of the atrioventricular (AV) node (arrow); (B) atrial septum hematoma $\left(^{*}\right)$ observed from the right side of the heart; $(\mathbf{C})$ histology (hematoxylin-eosin [HE] stain) showing the hemorrhage $\left(^{*}\right)$ spreading to the transitional zone of the AV node (arrowhead). (D) Patient 2: dissecting hematoma from the ascending aorta (AA) through the atrial septum (arrow): note the close relationship between the dissecting hematoma, the aortoatrial space, aortic valve and the AV junction (*); (E) necropsy specimen: the atrial septum hematoma (arrow) is well seen from the left atrium (LA) side (arrow); (F) histology (HE stain) of the mitroaortic continuity showing the dissecting hematoma reaching the AV node; $(\mathbf{G})$ dissecting hemorrhage infiltrating the periadventitial fibrous and fatty tissues of the right coronary artery (arrow). IAS, interatrial septum; LV, left ventricle; MV, mitral valve; RA, right atrium; RAA, right atrial appendage; RV, right ventricle; SV, sinus of Valsalva.

Received November 24, 2016; revised manuscript received February 1, 2017; accepted February 26, 2017; released online March 25, 2017 Time for primary review: 42 days

Department of Cardiology (J.C.G.-P., I.V., C.F., C.O., P.M.-L., D.V., F.J.N.-S., A.V.-T.), Department of Pathology (E.A.-N., G.G.-D., L.O.), San Carlos Clinical Hospital, Madrid; Department of Cardiology, La Paz University Hospital, Madrid (S.R.), Spain

Mailing address: Juan Carlos Gómez-Polo, MD, Department of Cardiology, Hospital Clínico San Carlos, c/- Professor Martín Lagos s/n, Madrid 28040, Spain. E-mail: jc.gomezpolo@gmail.com

ISSN-1346-9843 All rights are reserved to the Japanese Circulation Society. For permissions, please e-mail: cj@j-circ.or.jp 
A series of 2 consecutive patients were admitted to with acute chest pain and slight ST-segment elevation. In both cases a type A aortic dissection (AD) with extensive atrial septum hematoma was documented. Herein we review the literature and present some insights into this infrequent complication of acute AD.

Patient 1 was a 47-year-old man with morbid obesity, smoking habit, and a history of hypertension. He was transferred to the present hospital with ongoing chest pain. Electrocardiogram (ECG) showed slight ST elevation of the inferior leads, therefore the patient was taken directly to the catheterization laboratory. Angiography indicated a wavy flap corresponding to an acute type A AD. Coronary angiography was not attempted. Transthoracic echocardiogram showed normal left ventricular function, and no pericardial effusion or aortic regurgitation. Cardiac troponins were negative. While undergoing computed tomography $(\mathrm{CT})$ in the radiology department, prior to emergency surgery, the patient developed progressive bradycardia, pulseless electrical activity and asystole inside the CT device. Immediately, advanced resuscitation maneuvers were started, but temporary transvenous ventricular pacing was not possible in this particular setting. Transcutaneous temporary pacing was attempted but adequate capture was not achieved due to the patient's characteristics. After a prolonged time of advanced cardiopulmonary resuscitation including repeated adrenaline bolus and catecholamine use, the patient died.

Post-mortem examination confirmed the presence of type A AD with a portal of entry at the aortic root. The AD flap extended distally up to the abdominal aorta. Proximally, the dissecting hematoma penetrated into the aortoatrial space and an extensive interatrial hemorrhage could be observed (Figure A,B), extending to the whole area of the atrioventricular (AV) node (Figure C). The ostia of the coronary arteries were intact and there was no coronary artery dissection. No evidence of myocardial infarction (MI) was found. Neither pericardial hematoma nor evidence of supraortic branch involvement were seen.

Patient 2 was a 52-year-old man with no past cardiovascular history. He had an out-of-hospital cardiac arrest, with progressive bradycardia and asystole. He was assisted by the emergency services outside the hospital. Resuscitation maneuvers were rapidly started, and return to spontaneous circulation was achieved after $20 \mathrm{~min}$. ECG after pulse recovery showed slight ST-segment elevation of the inferolateral leads, therefore the patient was directly transferred to the catheterization laboratory. At hospital admission, in the emergency room, the patient had a second cardiac arrest. Severe bradycardia with wide-QRS escape beats was documented on ECG, followed by electromechanical dissociation. Although advanced resuscitation including catecholamine was performed, there was no chance for temporary ventricular pacing implantation, and the patient died. Post-mortem examination indicated bicuspid aortic valve and an intimo-medial flap from the ascending to the abdominal aorta, with an intimal tear located $2.5 \mathrm{~cm}$ above the aortic annulus. Some hematoma was noted on the epicardial surface of the heart around the origin of the right coronary artery (RCA). As in the previous case, the dissecting hematoma extended proximally through the interatrial septum (Figure E) and spread between the transitional cell area of the AV junction (Figure F). Moreover, extension of the hematoma around the proximal segment of the RCA infiltrating the periadventitial fat was also documented (Figure G). No clear-cut MI could be seen. No other complications from AD were found.

The present cases are 2 examples of type A AD complicated with atrial septum hematoma. Other potential complications of this threatening disease explaining sudden cardiac death such as cardiac tamponade, aortic rupture or neck vessel involvement were excluded. We reviewed the few cases reported in the literature and present some insights on the relevance of atrial septum hematoma in AD.

Acute aortic syndrome is included in the differential diagnosis of acute coronary syndrome. ${ }^{1} \mathrm{AV}$ block is a common complication of inferior MI. In this setting, AV node ischemia secondary to RCA occlusion is the most common mechanism. In acute AD, AV conduction disturbances may also be observed, but the pathogenetic mechanism is more variable and the occurrence of this complication is definitely more unusual. ${ }^{2}$ Progression of the dissection flap down to the RCA may produce AV block. ${ }^{3}$ RCA perfusion may also be compromised when the right coronary ostium is trapped in the aortic false lumen. ${ }^{4}$ Extensive myocardial fibrosis leading to AV block has been observed in type B AD with past history of severe hypertension. ${ }^{5}$

Another potential mechanism of AV block in AD is that observed in the present cases: that is, extension of the dissecting hematoma into the aortoatrial space, progressing down to the atrial septum and to the area of the central fibrous body of the heart. ${ }^{68}$ Here, hemorrhage may involve the transitional cell zone of the AV junction, producing heart block. ${ }^{8}$ Interestingly, since the first documentation of AV block in the setting of $\mathrm{AD},{ }^{6}$ and after reviewing the scarce literature on this subject, sparing of the compact zone of the AV node, as in the present cases, is the rule; $;$, 8 and, in some cases, eventual restoration to normal conduction has occurred. ${ }^{9}$

Hematoma of the right atrial wall and interatrial septum occurs after rupture of an adjacent high-pressure chamber or vessel into this space. In this situation, AV node response to catecholamine may be poor because of the structural damage. Insertion of an i.v. temporary pacing electrode is a reasonable alternative in these cases. After a few minutes of asystole or AV block without an adequate escape, however, severe metabolic acidosis prevents effective pacing. ${ }^{7}$

The mechanism underlying the slight ST-segment elevation of the inferior leads seen in the present cases is not clear. Spreading of the hematoma from the aortic root to the transverse sinus area and to neighboring structures may dissect the loosely fibrous and fatty tissues around the RCA (Figure G) producing some degree of vessel compression. In the few cases reported in the literature, clinicopathologic correlation has not been systematically performed, but in most cases cardiac enzymes were normal and there was no ST elevation. ${ }^{10,11}$ Alternatively, ST elevation might be due to atrial wall and atrial septum injury.

Based on these findings and according to the literature, we can conclude that syncope in AD can be due to AV block. Impaired RCA perfusion is the most common mechanism. Atrial septum hematoma is another potential mechanism of AV block in acute AD. It should be suspected when there is no clear ST elevation, or it is very mild and myocardial enzymes are negative. 


\section{Acknowledgments}

None.

\section{References}

1. Vilacosta I, Aragoncillo P, Cañadas V, San Román JA, Ferreirós J, Rodríguez E. Acute aortic syndrome: A new look to an old conundrum. Heart 2009; 95: 1130-1139.

2. Kosuge M, Uchida K, Imoto K, Hashiyama N, Ebina T, Hibi K, et al. Frequency and implication of ST-T abnormalities on hospital admission electrocardiograms in patients with type A acute aortic dissection. Am J Cardiol 2013; 112: 424-429.

3. Kamp TJ, Goldschmidt-Clermont PJ, Brinker JA, Resar JR. Myocardial infarction, aortic dissection, and thrombolytic therapy. Am Heart J 1994; 128: 1234-1237.

4. Chen A, Ren X. Aortic dissection manifesting as ST-segmentelevation myocardial infarction. Circulation 2015; 131: e503e504.

5. Lionakis N, Moyssakis I, Gialafos E, Dalianis N, Votteas V. Aortic dissection and third-degree atrioventricular block in a patient with a hypertensive crisis. J Clin Hypertens 2008; 10: 69-72.

6. Pick A, Mininni G. The mechanism of sudden death in dissecting aneurysm with intracardiac rupture. Br Heart $J$ 1953; 15: 369-375.

7. Yacoub MH, Schottenfeld M, Kittle CF. Hematoma of the interatrial septum with heart block secondary to dissecting aneurysm of the aorta: A clinicopathologic entity. Circulation 1972; 46: 537-545.

8. Thiene G, Rossi L, Becker AE. The atrioventricular conduction system in dissecting aneurysm of the aorta. Am Heart J 1979; 98: $447-452$.

9. Lorenzoni R, Santoro GM, Calamai G, Masini G. Complete atrioventricular block as main clinical manifestation of an undiagnosed aortic dissection. G Ital Cardiol 1995; 25: 1031-1035.

10. Jessen ME, Horn VPH, Weaver DE, Boehrer JD, Ring WS Successful surgical repair of aortic dissection presenting with complete heart block. Ann Thorac Surg 1996; 62: 1202-1203.

11. Fujiwara H, Matsuki K. Complete atrioventricular block subsequent to thrombosed-type acute aortic dissection. Gen Thorac Cardiovasc Surg 2012; 60: 302-304. 